\title{
AN EXPERIMENTAL STUDY ON HEAT TRANSFER AND FRICTION FACTOR OF $\mathrm{AL}_{2} \mathrm{O}_{3}$ NANOFLUID
}

\author{
L. Syam Sundar ${ }^{1}$ and K.V. Sharma ${ }^{2}$ \\ ${ }^{1}$ Centre for Energy Studies, JNTUH College of Engineering, Kukatpally, Hyderabad \\ 500085, India, Tel./Fax. +91-40-32408715/+91-40-23058720 \\ E-mail: sslingala@ rediffmail.com \\ ${ }^{2}$ Faculty of Mechanical Engineering, Universiti Malaysia Pahang, 26600 Pekan, \\ Pahang, Malaysia Tel./Fax. +6-09-4242324/+6-09-4242202 \\ E-mail: kvsharmajntu@gmail.com
}

\begin{abstract}
This paper reports experimental investigations of fully developed laminar convective heat transfer and friction factor characteristics of different volume concentrations of $\mathrm{Al}_{2} \mathrm{O}_{3}$ nanofluid in a plain tube, fitted with different twist ratios of twisted tape inserts. Experiments are conducted with water and nanofluid in the range of $700<\operatorname{Re}<2200$, particle volume concentration of $0<\varphi<0.5 \%$, and twisted tape twist ratios of $0<H / D<15$. The heat transfer coefficient of the nanofluid is high compared with water, and further enhancement of heat transfer is observed with the twisted tape inserts. Pressure drop is slightly increased with the inserts, but is comparatively negligible. A generalized regression equation is developed based on the experimental data for the estimation of the Nusselt number and friction factor for water and nanofluid in a plain tube with twisted tape inserts.
\end{abstract}

Keywords: forced convection in a tube, aluminum oxide nanofluid, twisted tape inserts, heat transfer enhancement, nanofluid friction factor.

\section{INTRODUCTION}

The low thermal conductivity of conventional heat transfer fluids, such as water, oil, and ethylene glycol, is a serious limitation to the improvement of the performance and compactness of many engineered products, such as heat exchangers. Initial experiments have been performed with small-sized metallic particles, which possess high thermal conductivity, to enhance heat transfer. Early research on the suspension of these micrometer-sized particles identified problems associated with dispersion and flow. To overcome this, nano-sized particles were developed, dispersed in a base liquid, and the thermal conductivity enhancement obtained (Choi, 1995). The thermo-physical properties of different volume concentrations of nanofluid have been explained (Masuda, Ebata, Teramae, \& Hishinuma, 1993; Pak \& Cho, 1998; Eastman, Choi, Li, Soyez, Thompson, \& DiMelfi, 1999; Eastman, Choi, Li, Yu, \& Thompson, 2001; Lee, Choi, Li, \& Eastman, 1999; Wang, Xu, \& Choi, 1999; Das, Putra, Thiesen, \& Roetzel, 2003).

The enhancement of thermal conductivity is confirmed by using $\mathrm{Al}_{2} \mathrm{O}_{3}, \mathrm{TiO}_{2}$, and $\mathrm{Cu}$ nanoparticles dispersed in water (Pak \& Cho, 1998; Xuan \& Li, 2003). They also estimated the heat transfer coefficients and pressure drop in tubes, under turbulent flow with nanofluids at different concentrations. The heat transfer coefficients are observed to increase with concentration when compared with base liquid water. The 
authors have presented regression equations for the estimation of the Nusselt numbers. Numerical studies have been undertaken (Namburu, Das, Tanguturi, \& Vajjha, 2009) with $\mathrm{CuO}, \mathrm{Al}_{2} \mathrm{O}_{3}$, and $\mathrm{SiO}_{2}$ nanofluids under turbulent flow, which obtained higher heat transfer coefficients compared with water. Experimentally, Wen and Ding (2004) observed that $\mathrm{Al}_{2} \mathrm{O}_{3}$ nanoparticles, when dispersed in water, show enhancements in the coefficients of laminar convective heat transfer. Experiments conducted by Heris, Esfahany and Etemad (2007) with $\mathrm{Al}_{2} \mathrm{O}_{3}$ /water nanofluid in the laminar flow range of Reynolds number, subject to isothermal wall boundary conditions, predicted higher values of heat transfer. The enhancements were found to increase with Reynolds number as well as with particle concentration. Numerical studies have been undertaken in the laminar range with $\mathrm{Al}_{2} \mathrm{O}_{3}$ /water $\mathrm{Al}_{2} \mathrm{O}_{3}$ /ethylene glycol nanofluids and the heat transfer enhancement obtained.

The numerical analysis of laminar flow heat transfer of $\mathrm{Al}_{2} \mathrm{O}_{3}$ /ethylene glycol and $\mathrm{Al}_{2} \mathrm{O}_{3}$ /water nanofluids in tubes has been reported (Palm, Roy, \& Nguyen, 2004; Roy, Nguyen, \& Lajoie, 2004) and it was observed that wall shear stress increased with volume concentration and Reynolds number. The enhancement of heat transfer with flow of nanofluids in a tube has been summarized by Wang and Majumdar (2007), and Kakaç and Pramuanjaroenkij (2009). Passive enhancement of heat transfer can also be achieved with the use of twisted tape inserts for flows in a tube or duct. Heat transfer enhancements have been determined through experiment and numerical analysis for the flow of single-phase fluids in a tube, which are valid for a wide range of Reynolds number (Smithberg \& Landis, 1964; Lopina \& Bergles, 1969; Lecjaks, Machac, \& Sir, 1987; Sarma, Subramanyam, Kishore, Dharma Rao, \& Kakac, 2003). Experiments have determination the heat transfer using twisted tape inserts in a tube with $\mathrm{Al}_{2} \mathrm{O}_{3}$ nanofluid at different volume concentrations (Sharma, Sundar, \& Sarma, 2009; Sundar \& Sharma, 2010). They have presented empirical correlations for the estimation of the Nusselt number and friction factor in the transition and turbulent flow range. The equation proposed by them has the flexibility to estimate the Nusselt number for the flow of water or nanofluid in a plain tube and with twisted tape inserts. Nanofluid heat transfer and pressure drop in the laminar range of Reynolds number with twisted tape inserts has not yet been estimated. The experimental determination of these parameters is undertaken in the present study.

\section{EXPERIMENTAL SETUP AND PROCEDURE}

The schematic diagram of the experimental setup is shown in Figure 1a. The fluid flows through a copper tube of $0.012 \mathrm{~m}$ diameter to a chiller or collecting tank and a storage tank under the action of a pump. The copper tube is heated uniformly by wrapping it in two 20 -gauge nichrome heaters, having a resistance of $53.5 \Omega$ per meter length and $1000 \mathrm{~W}$ maximum rating, and subject throughout the entire test section to a constant heat flux boundary condition. The space between the test section and the outer casing is stuffed with rock wool insulation to minimize heat loss to the atmosphere. The $1.5-\mathrm{m}$ length test section is provided with five K-type thermocouples; three brazed to the surface at distances of $0.375,0.75$, and $1.125 \mathrm{~m}$ from the entry and two more located to measure the working fluid inlet and outlet temperatures. All these thermocouples have $0.1{ }^{\circ} \mathrm{C}$ resolution and they are calibrated before fixing them at the specified locations. The aspect ratio of the test section is sufficiently large for the flow to be hydrodynamically developed. The fluid is forced through the test section under the action of a pump; the suction side is connected to a storage tank. The storage tank is 
made of stainless steel with a capacity of 30 liters. The liquid, which is heated in the test section, is allowed to cool by passing it through a chiller. The liquid is then gravity-fed into the storage tank. The provision of the chiller reduces the time required to achieve steady state conditions.

The twisted tapes are made in the laboratory from a 1-mm thick and $0.01-\mathrm{m}$ radius aluminum strip, as shown in Figure 1b. The dimensions of the twisted tape inserts are shown in Table 1. The two ends of a strip were held on a lathe, one at the headstock end and the other at the tailstock end by special devices made in the laboratory. The strip was then subjected to twisting by turning the chuck manually. Four twist ratios of $\mathrm{H} / \mathrm{D}=5,10$, and 15 were fabricated. Twisted tapes are fitted tightly into the tube and the tape fin effect is neglected.

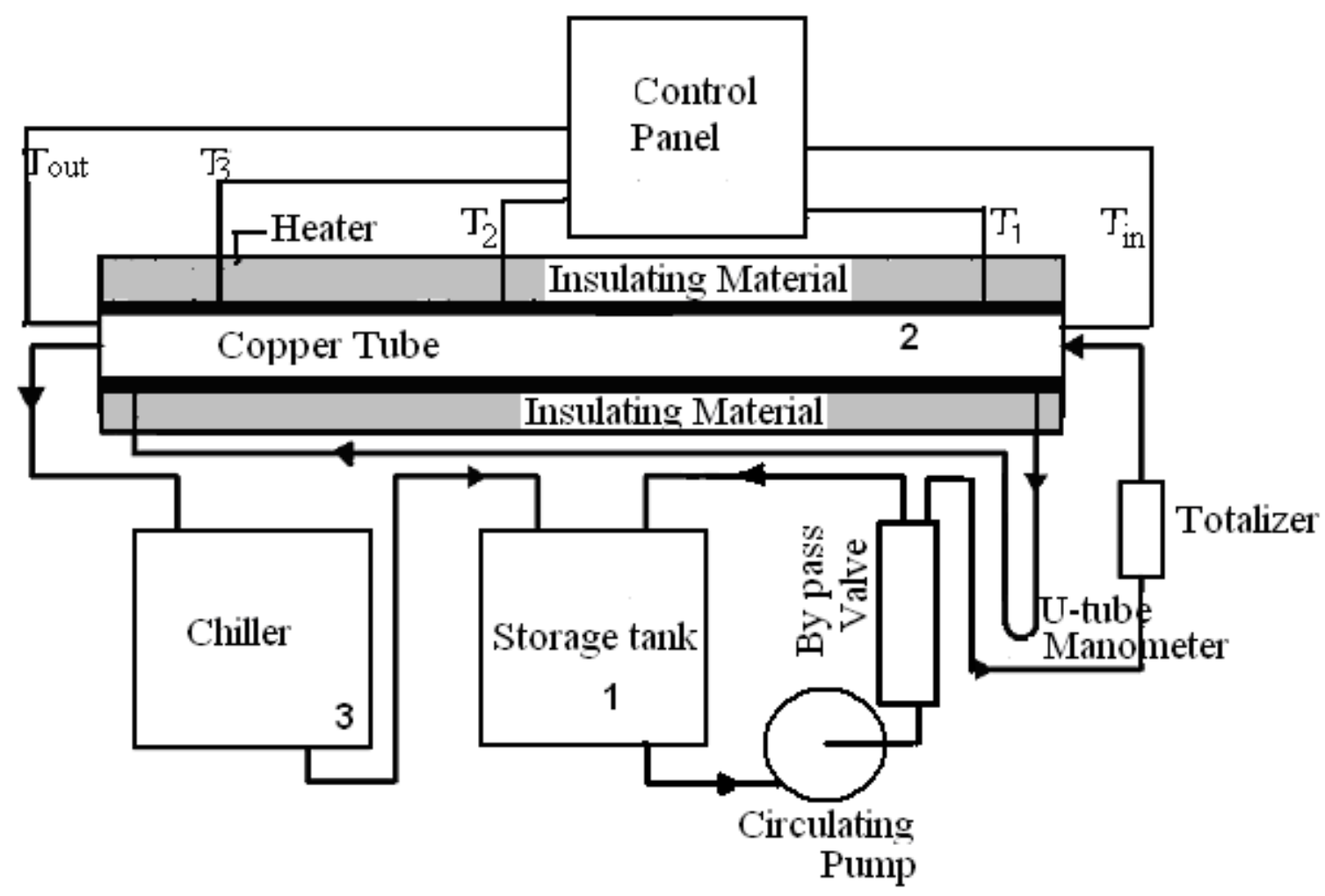

Figure 1a. Schematic diagram of the experimental setup
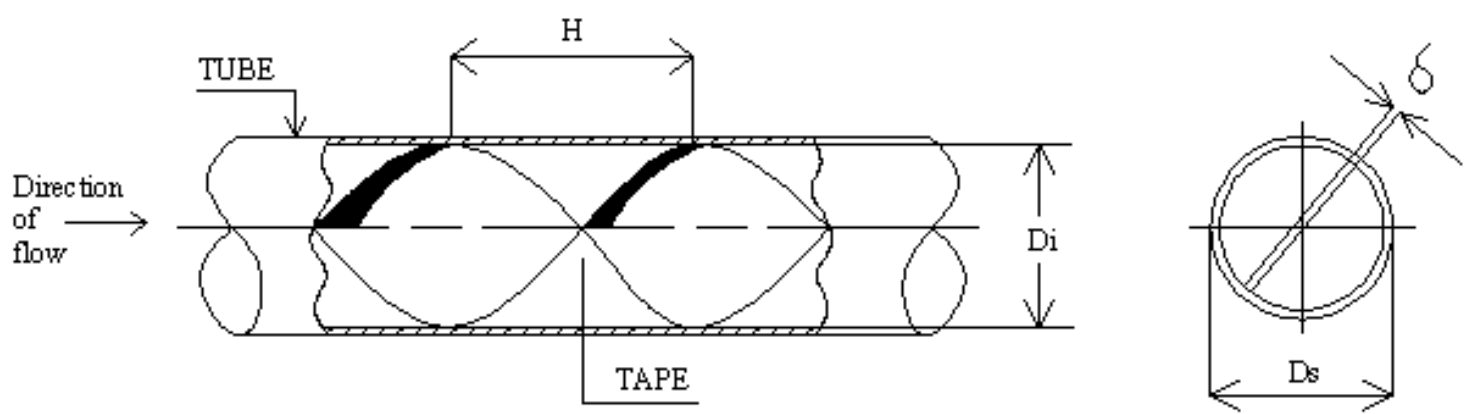

Figure 1b. Full-length twisted tape insert inside a tube 
Once the experimental setup is assembled, the storage tank is filled with the working fluid. Experiments are conducted with water and nanofluids to determine the friction factor and heat transfer coefficients for flow in a tube. The procedure for the preparation of nanofluids is followed as described by Sundar, Ramanathan, Sharma and Sekhar Babu (2007). Nanofluids at different volume concentrations of $0.02 \%, 0.1 \%$, and $0.5 \%$ are used in conducting the experiments.

Table 1. Dimensions of twisted tape inserts

\begin{tabular}{lllll}
\hline \multirow{2}{*}{ S. No. } & \multirow{2}{*}{ Parameter } & \multicolumn{3}{l}{ Twist Ratio, H/D, m } \\
& & 5 & 10 & 15 \\
\hline 1 & H (Width) & 0.05 & 0.1 & 0.15 \\
2 & D (Diameter) & 0.01 & 0.01 & 0.01 \\
\hline
\end{tabular}

The working fluid flow rate in the test section is evaluated from the flow meter readings and validated manually. The properties of the fluid are evaluated at the mean temperature, as explained by Sundar and Sharma (2008). The required data for the estimation of the heat transfer coefficients and friction factor are recorded at different flow Reynolds numbers, ranging from 700 to 2200, with flow of water and nanofluid in a tube. A similar procedure is adopted for flow with longitudinal strip inserts and relevant comparisons are made. The heat transfer coefficient is estimated using Newton's law of cooling.

\section{RESULTS AND DISCUSSION}

\section{Nusselt number of water and nanofluid in plain tube}

The balance between the energy supplied by heating and the energy absorbed by the flowing liquid is established using Eqs. (1) and (2) for each set of data and the experimental heat transfer coefficient estimated using Eq. (3).

$$
\begin{aligned}
& Q=V \times I \text { (Energy supplied) } \\
& Q=m \times C \times\left(T_{0}-T_{i}\right)(\text { Energy absorbed }) \\
& h_{\text {Exp }}=\frac{Q}{A\left(T_{\text {wall }}-T_{\text {mean }}\right)}, A=\Pi D_{i} L, N u_{E x p}=\frac{h D_{i}}{k}
\end{aligned}
$$

The deviation between the values obtained with Eqs. (1) and (2) is less than $\pm 2.5 \%$ and the heat loss to the atmosphere is neglected. The experimental Nusselt numbers of the fully developed laminar flow with different volume concentrations of nanofluid is shown in Figure 2, together with the data for water. From this figure, it can be observed that the Nusslet number increases with an increase in the volume concentration of nanofluid under the same Reynolds number. The reason for heat transfer enhancement of the nanofluid is due to the effect of thermo-physical properties. Comparatively, the thermo-physical properties are greater for the nanofluid. 


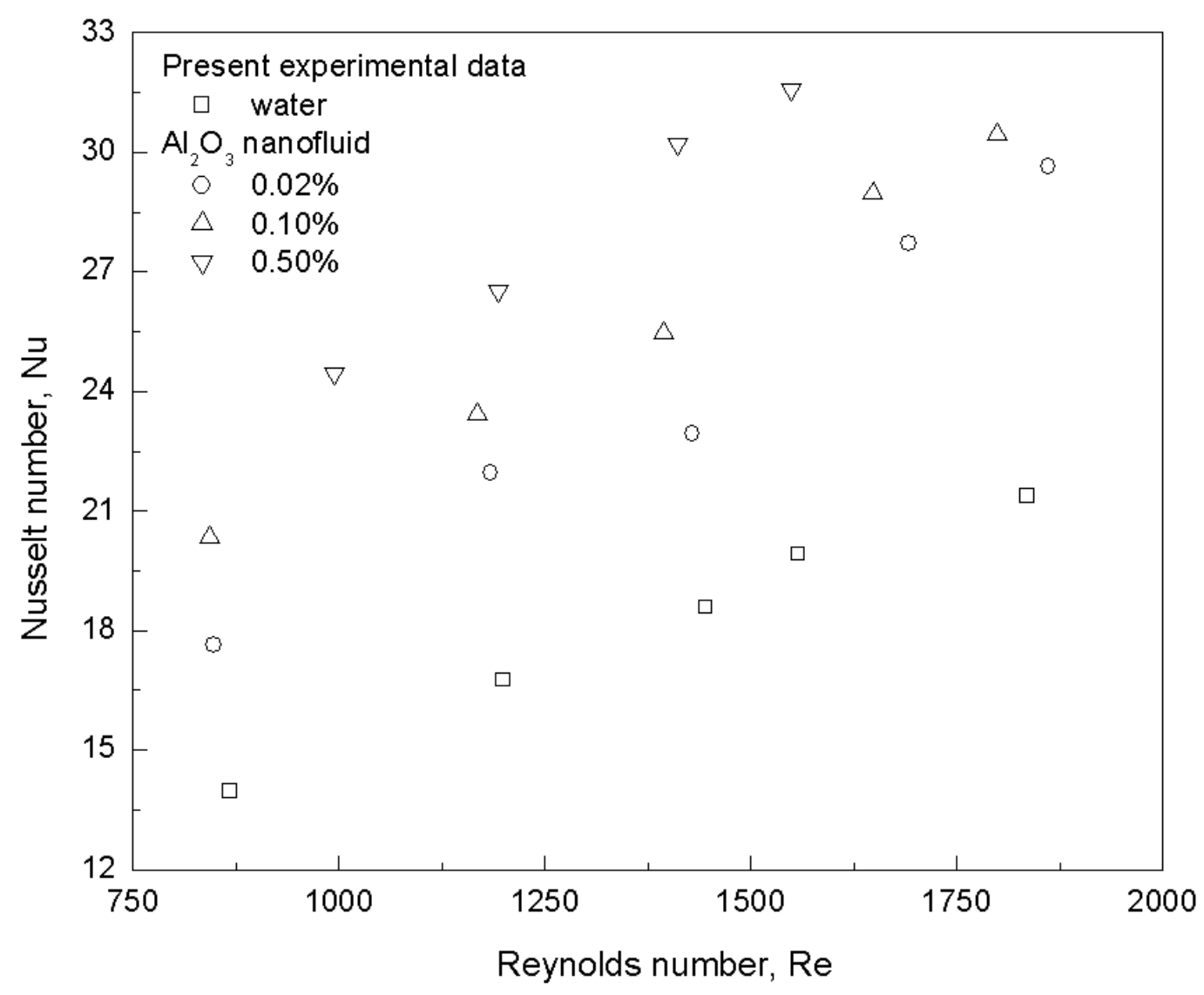

Figure 2. Experimental Nusselt number for water and for different volume concentrations of nanofluid

The equation for the estimation of the Nusselt number for different volume concentrations of $\mathrm{Al}_{2} \mathrm{O}_{3}$ nanofluid in a plain tube under fully developed laminar flow is obtained with an average deviation (AD) of $2.46 \%$ and standard deviation (SD) of $3.23 \%$, given by:

$$
N u_{\text {Re } g}=0.2624 \operatorname{Re}^{0.5860} \operatorname{Pr}^{0.3}(0.001+\varphi)^{0.07094}
$$

Valid in the range $700<\operatorname{Re}<2200,0<\varphi<0.5 \%$,

The values estimated from Eq. (4) are shown in Figure 3, together with the experimental Nusselt number of water and nanofluid. 


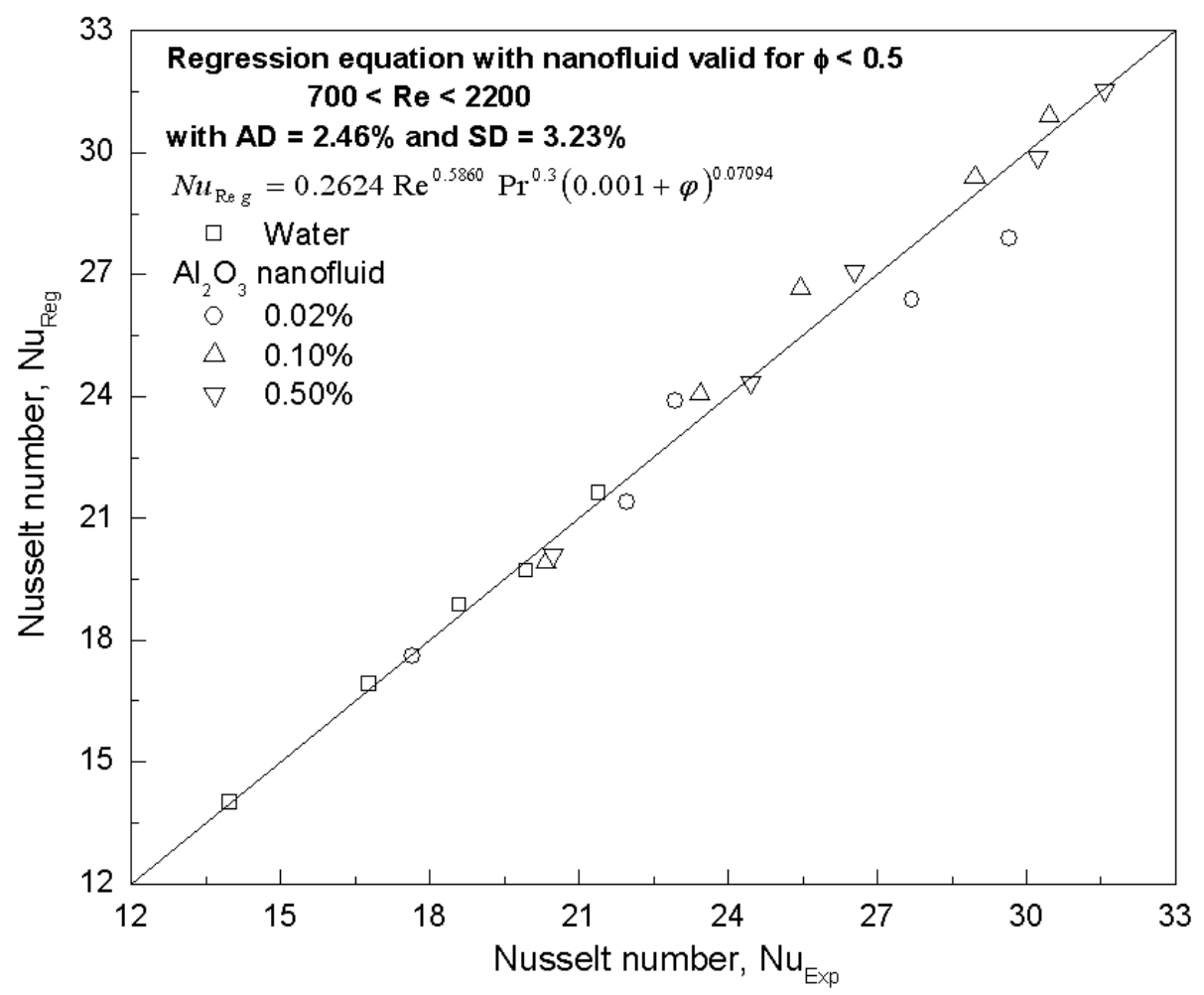

Figure 3. Experimental Nusselt number compared with Eq. (4)

\section{Nusselt number of water and nanofluid in plain tube with twisted tape inserts}

Experiments with twisted tape inserts are conducted with water and nanofluid following the procedure explained earlier for flow in a tube. The procedure is repeated with tapes of different twist ratios: 5, 10, and 15. The equation (Sarma et al., 2003) based on theoretical analysis and obtained with a standard deviation of $4 \%$ and average deviation of $3 \%$ for the estimation of the Nusselt number, is given by:

$$
N u_{\text {Reg }}=0.2036 \operatorname{Re}^{0.55} \operatorname{Pr}^{0.3}\left(1.0+\frac{D}{H}\right)^{4.12}
$$

This is valid in the range $100<\operatorname{Re}<3000,5<\operatorname{Pr}<400,2.5<H / D<10$ for pure liquids.

The experimental Nusselt number of water and nanofluid for flow in a tube with twisted tape inserts is presented in Figure 4; however, no literature is available with which to compare the data. From the figure, it can be observed that higher heat transfer rates are obtained with twisted tape inserts compared with nanofluid flow in a tube. The experimental Nusselt number of water and nanofluid in a plain tube with different twist ratios of twisted tape inserts is shown in Figure 5. 


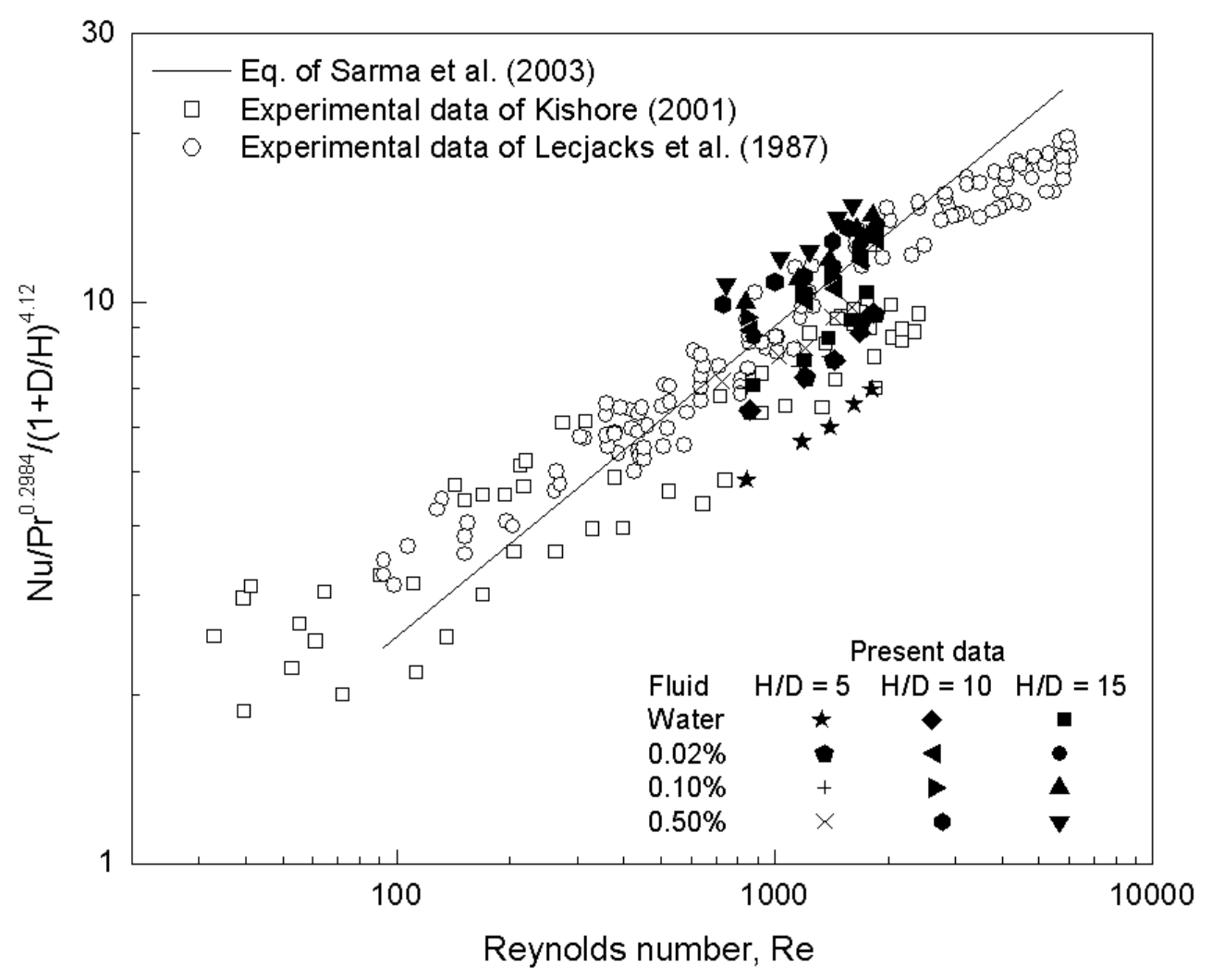

Figure 4. Comparison of present experimental data of water and nanofluid with twisted tape inserts with data available in the literature

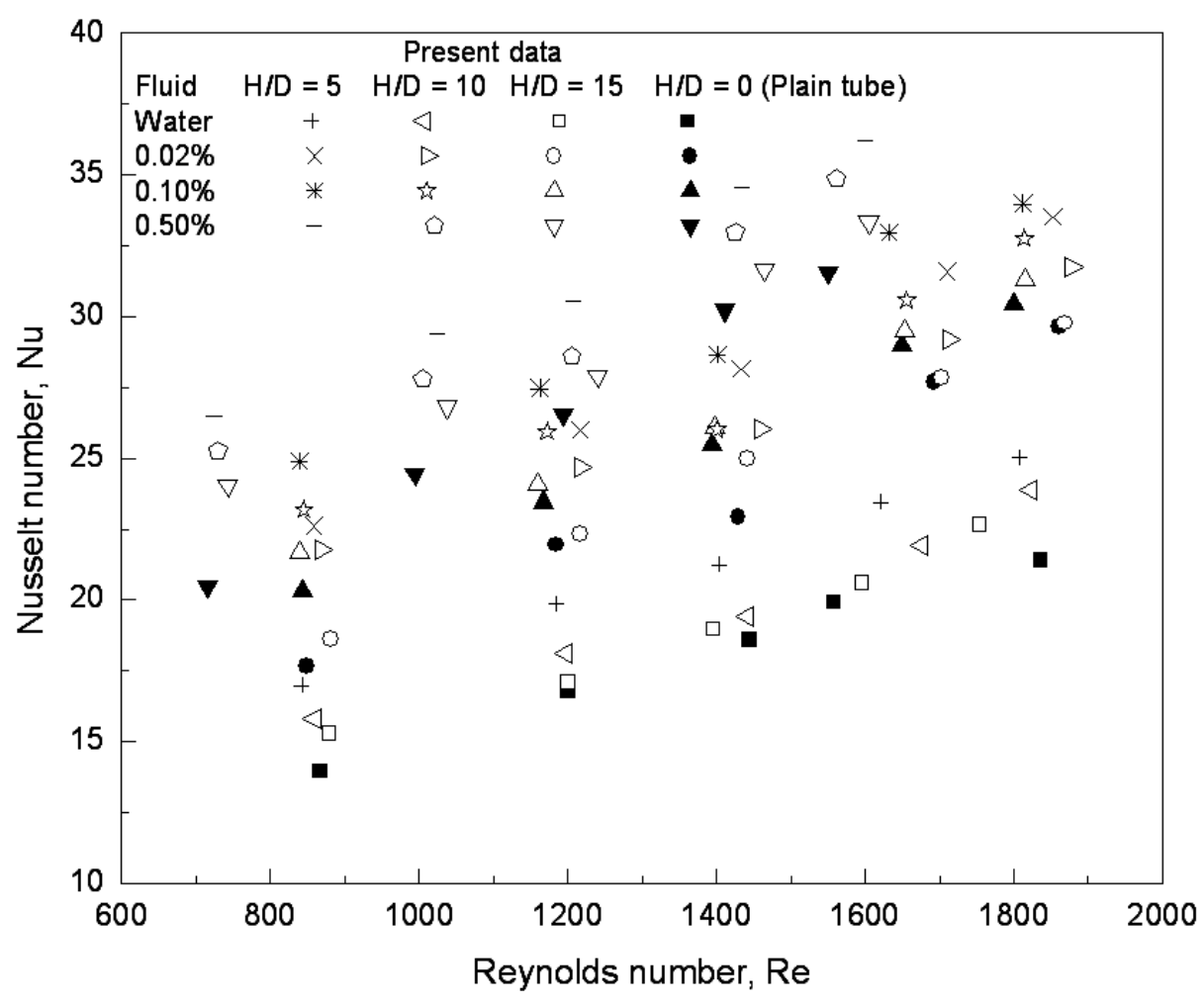

Figure 5. Experimental Nusselt number of water and nanofluid in plain tube with twisted tape inserts 
Hence, the present data for the flow of water and $\mathrm{Al}_{2} \mathrm{O}_{3}$ nanofluid in a tube with twisted tape inserts is subjected to regression and the equation is obtained with an average deviation $(\mathrm{AD})$ of $4.14 \%$ and standard deviation $(\mathrm{SD})$ of $5.23 \%$, given by:

$$
N u_{\text {Reg }}=0.5652 \operatorname{Re}^{0.5004} \operatorname{Pr}^{0.3}(0.001+\phi)^{0.07060}\left(0.001+\frac{D}{H}\right)^{0.02395}
$$

This is valid in the range $700<\operatorname{Re}<22000<\varphi<0.5 \%, 4.4<\operatorname{Pr}<6.5$, $0<H / D<15$ ( $\phi=0$ for water, $H / D=0$ for plain tube). The values of the Nusselt numbers estimated with Eq. (6) are in good agreement with the experimental values shown in Figure 6; thus, validating the developed regression equation.

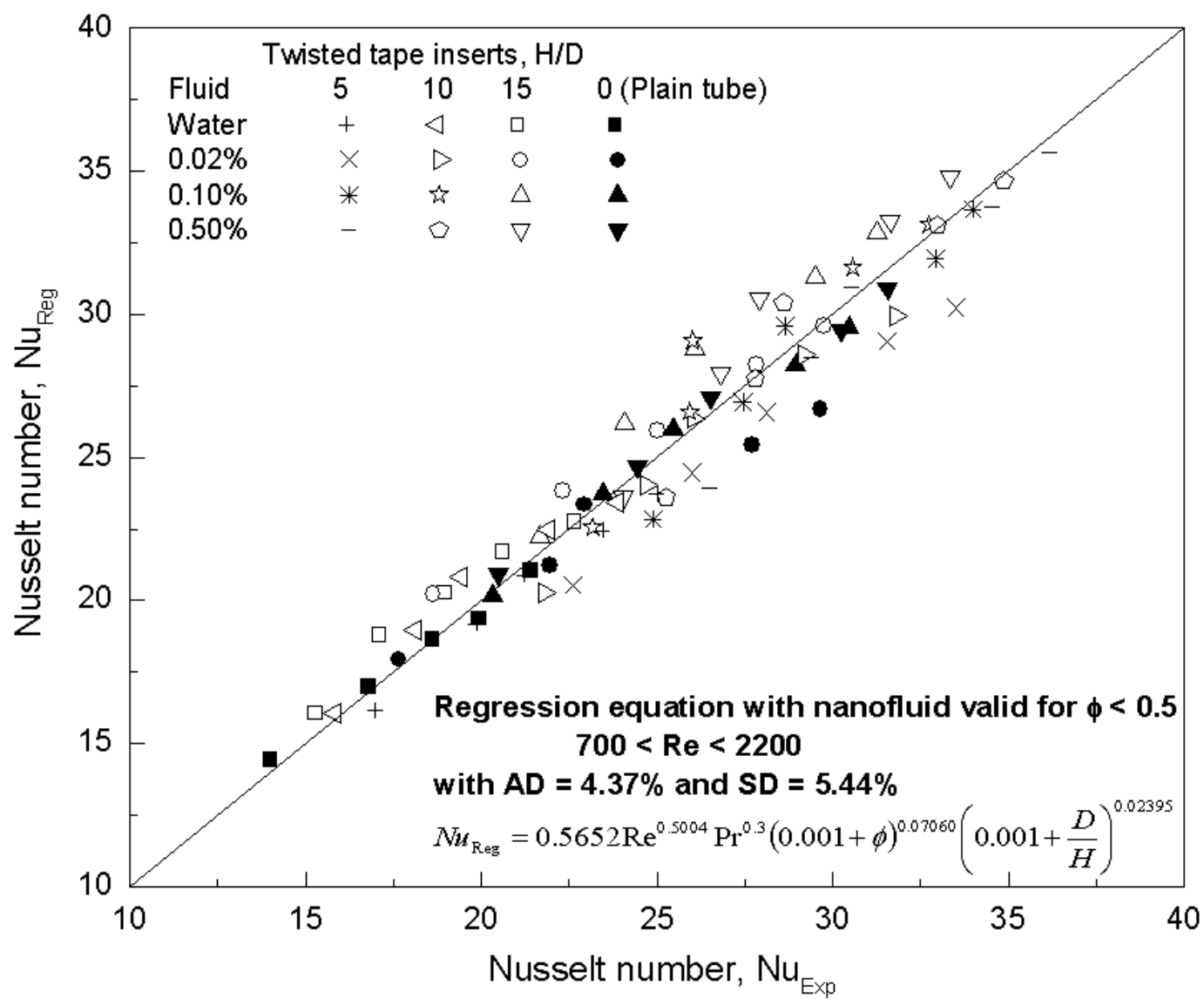

Figure 6. Comparison of experimental Nusselt numbers with Eq. (6)

\section{Friction Factor of Water and Nanofluid in a Plain Tube}

The friction factor can be determined from the relation:

$$
f=\frac{\Delta P}{\left(\frac{L}{D}\right)\left(\frac{\rho V^{2}}{2}\right)}
$$


where the single-phase fluid friction factor is (Moody, 1944):

$$
f=\frac{64}{\operatorname{Re}}
$$

The experimental friction factor of water and different volume concentrations of nanofluid estimated from Eq. (7) is compared with the values estimated from Eq. (8) and shown in Figure 7. It is evident that the friction factor values for the nanofluid are all the same as the values for water, which means that with the addition of solid particles in the base fluid there is not much enhancement of the friction factor.

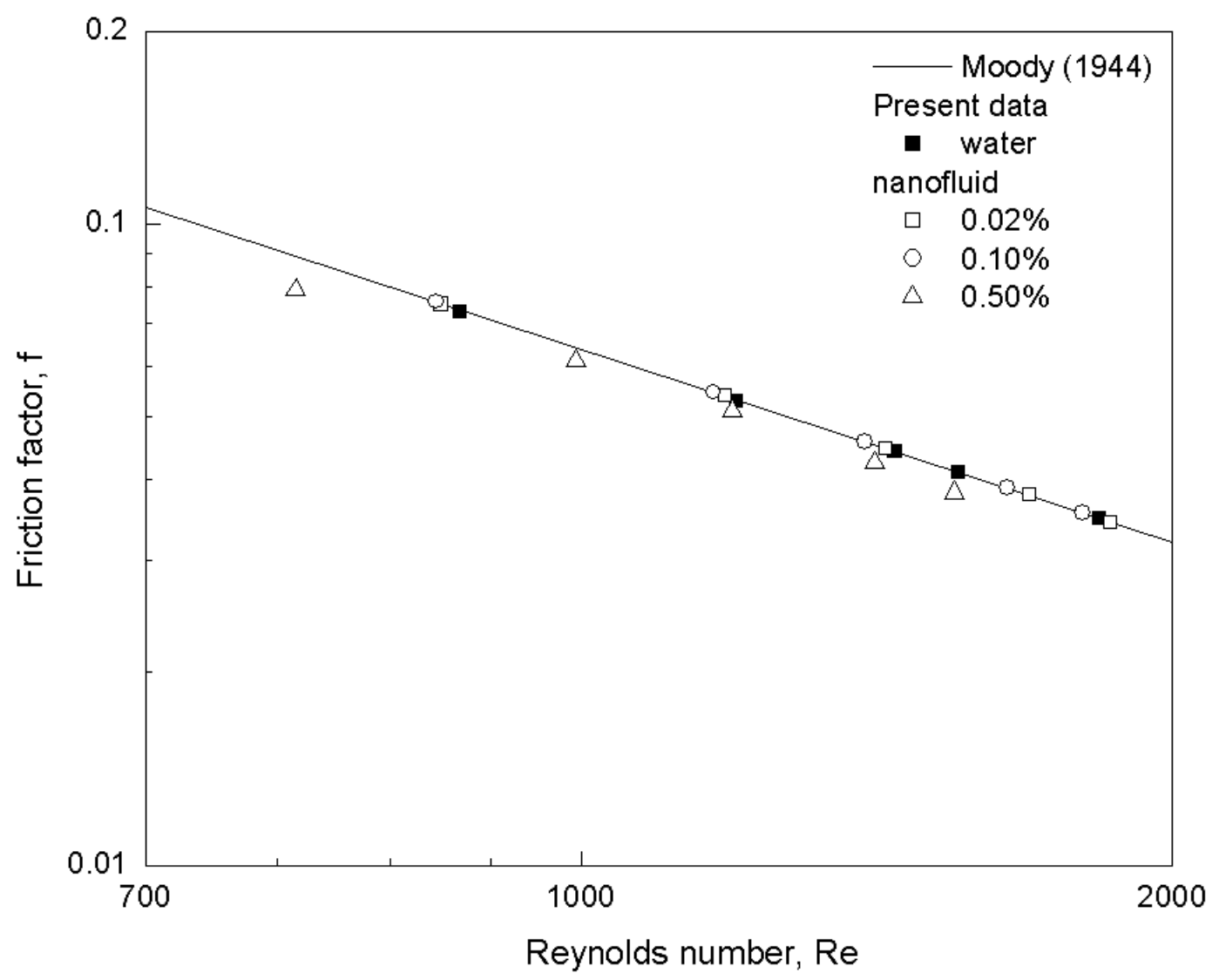

Figure 7. Comparison of experimental friction factor in plain tube with Moody's (1944) equation

A generalized regression equation is developed for the estimation of the friction factor of water and different volume concentrations of nanofluid in a plain tube under fully developed laminar flow conditions with an average deviation (AD) of $4.552 \%$ and standard deviation (SD) of $5.799 \%$, given by:

$$
f_{\operatorname{Re} g}=39.54 \operatorname{Re}^{-0.9316}(0.001+\varphi)^{0.01}
$$

This is valid for $700<\operatorname{Re}<2200,4.4<\operatorname{Pr}<6.5,0<\varphi<0.5$. 
The values of the friction factor estimated with Eq. (9) are in good agreement with the experimental values shown in Figure 8; thus, validating the developed equation.

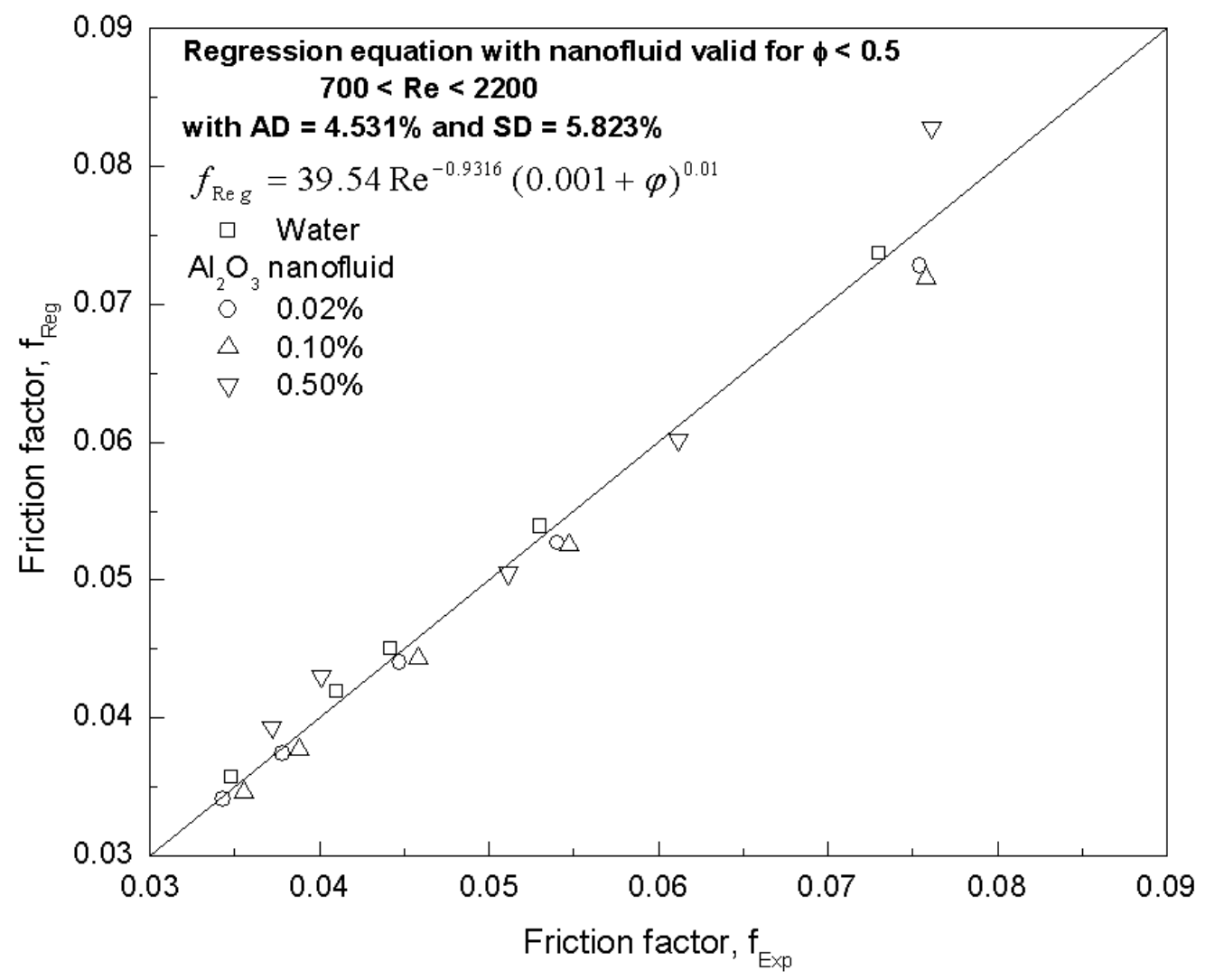

Figure 8. Comparison of experimental friction factor with Eq. (9)

\section{Friction Factor of Water and Nanofluid with and without Twisted Tape Inserts}

Equation (7) is used to estimate the experimental friction factor of water and nanofluid in a plain tube with twisted tape inserts, and the data are presented in Figure 9; however, no literature is available with which to compare the data. It is evident that higher friction factors are obtained with twisted tape inserts than with flow in a tube either for water or for nanofluid.

The present data of friction factor are subjected to regression and obtained with an average deviation (AD) of $4.886 \%$ and standard deviation (SD) of $6.221 \%$, given by:

$$
f_{\operatorname{Re} g}=52.08 \operatorname{Re}^{-0.9641}(0.001+\varphi)^{0.01}\left(0.001+\frac{D}{H}\right)^{0.006120}
$$

This is valid for the range $700 \leq \operatorname{Re} \leq 2200,4.4 \leq \operatorname{Pr} \leq 5.5,0 \leq \phi \leq 0.5,0 \leq(H / D) \leq 15$ ( $\phi=0$ for water, $H / D=0$ for plain tube). The values of friction factor estimated with Eq. (10) are in good agreement with the experimental values shown in Figure 10; thus, validating the developed equation. 


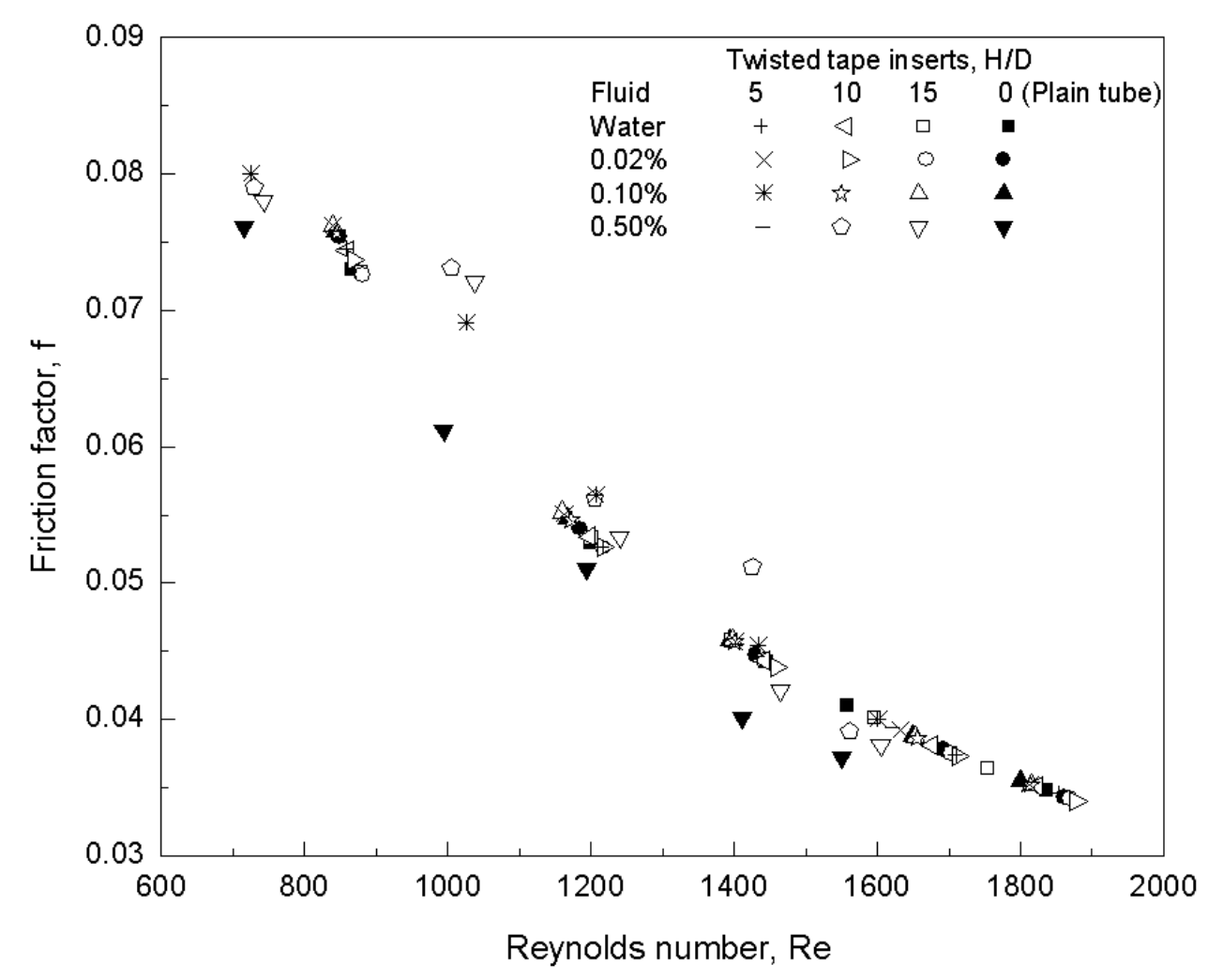

Figure 9. Friction factor of water and nanofluid in plain tube with twisted tape inserts.

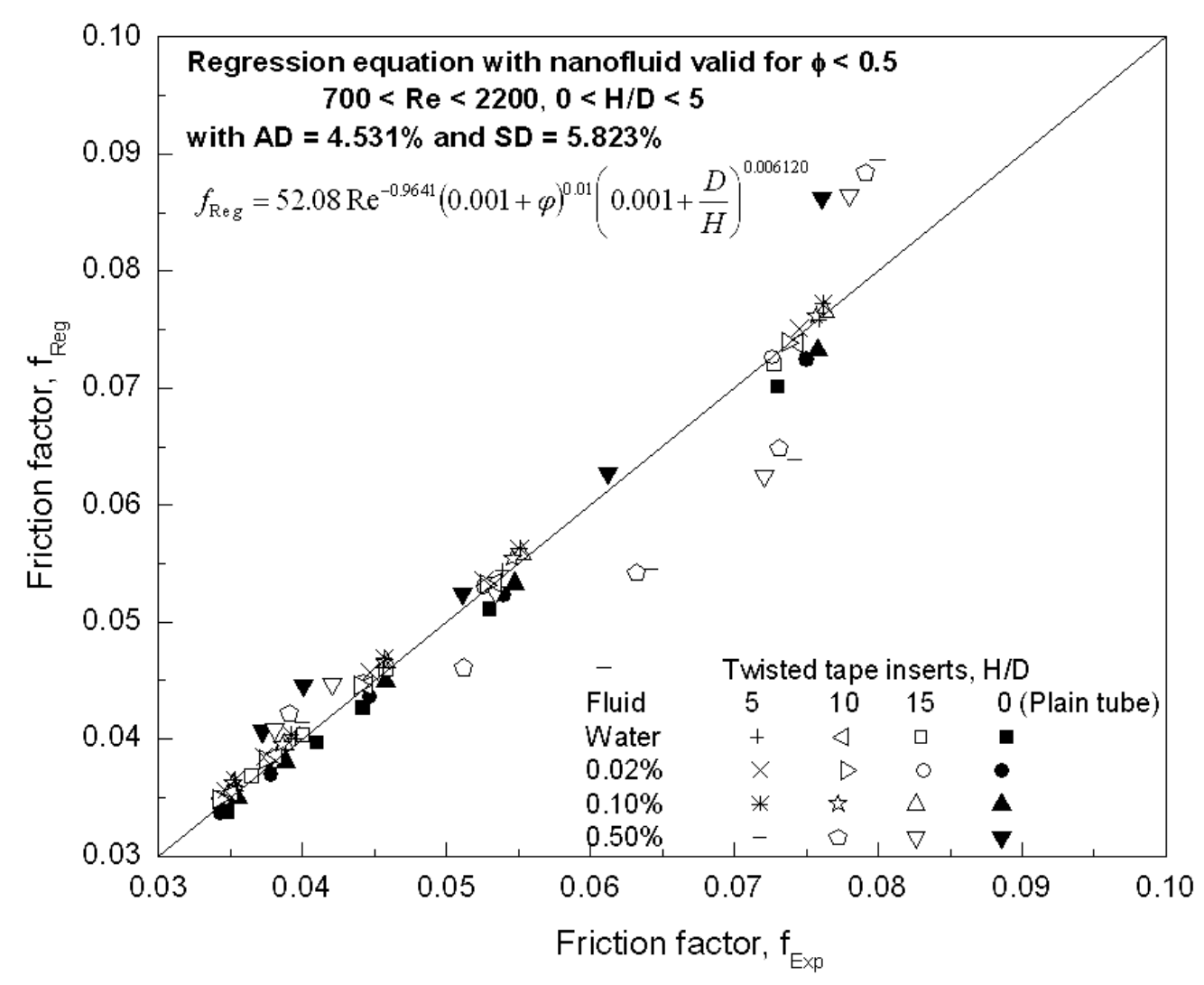

Figure 10. Comparison of experimental friction factor with Eq. (10). 


\section{CONCLUSIONS}

The enhancement of heat transfer in a plain tube with $0.5 \%$ volume concentration of $\mathrm{Al}_{2} \mathrm{O}_{3}$ nanofluid compared with water for a Reynolds number of 700 and 2200 is $46.52 \%$ and $47.59 \%$, respectively. The enhancement of friction factor in a plain tube with $0.5 \%$ volume concentration of $\mathrm{Al}_{2} \mathrm{O}_{3}$ nanofluid when compared with water for a Reynolds number of 700 and 2200 is 1.042 and 1.068 times, respectively. The heat transfer coefficient of $0.5 \%$ volume concentration $\mathrm{Al}_{2} \mathrm{O}_{3}$ nanofluid with twisted tape inserts having $(H / D)=5$ is $14.60 \%$ and $29.50 \%$ greater for a Reynolds number of 700 and 2200 , respectively, compared with the same fluid, and $69.14 \%$ and $89.76 \%$ greater compared with water flowing in a plain tube. The friction factor of $0.5 \%$ volume concentration $\mathrm{Al}_{2} \mathrm{O}_{3}$ nanofluid with twisted tape inserts having $(H / D)=5$ is 1.0958 times greater for a Reynolds number of 700 and 1.0652 times greater for a Reynolds number of 2200 when compared with water and 1.512 and 1.0412 times greater compared with the same fluid flowing in a tube. The use of twisted tape inserts is advantageous at higher Reynolds numbers based on the values of friction factor and heat transfer compared with flow in a tube either for water or for nanofluid. The use of the nanofluid enhances the heat transfer coefficient with no significant enhancement in pressure drop compared with water in the range tested. The experimental data of friction and Nusselt number of water and $\mathrm{Al}_{2} \mathrm{O}_{3}$ nanofluid for flow in a plain tube and with longitudinal strip insert can be presented, respectively, as:

$$
\begin{aligned}
& f_{\operatorname{Re} g}=52.08 \operatorname{Re}^{-0.9641}(0.001+\varphi)^{0.01}\left(0.001+\frac{D}{H}\right)^{0.006120} \\
& N u_{\operatorname{Reg}}=0.5652 \operatorname{Re}^{0.5004} \operatorname{Pr}^{0.3}(0.001+\phi)^{0.07060}\left(0.001+\frac{D}{H}\right)^{0.02395} .
\end{aligned}
$$

\section{REFERENCES}

Choi, S. U. S. (1995). Enhancing thermal conductivity of fluid with nanoparticles. In: Siginer, D.A., Wang, H.P. (Eds.), Developments and Applications of NonNewtonian Flows, FED-V.231/ MD-V.66. ASME, New York, 99-105.

Das, S. K, Putra, N., Thiesen, P., \& Roetzel, W. (2003). Temperature dependence of thermal conductivity enhancement for nanofluids. Journal of Heat Transfer, $125,567-574$.

Eastman, J. A., Choi, S. U. S., Li, S., Soyez, G., Thompson, L. J., \& DiMelfi, R. J. (1999). Novel thermal properties of nanostructured materials. Journal of Metastable Nanocrystal Materials, 2(6), 629-634.

Eastman, J. A., Choi, S. U. S., Li, S., Yu, W., \& Thompson, L. J. (2001). Anomalously increase effective thermal conductivities of ethylene glycol-based nanofluids containing copper nanoparticles. Applied Physics Letter, 78(6), 718-720.

Heris, S. Z., Esfahany, M. N., \& Etemad, G. S. (2007). Experimental investigation of convective heat transfer of $\mathrm{Al}_{2} \mathrm{O}_{3}$ /water nanofluid in circular tube. International Journal of Heat and Fluid Flow, 28, 203-210. 
Kakaç, S., \& Pramuanjaroenkij, A. (2009). Review of convective heat transfer enhancement with nanofluids. International Journal of Heat and Mass Transfer, 52, 3187-3196.

Lecjaks, Z., Machac, I., \& Sir, J. (1987). Heat transfer to a Newtonian liquid flowing through a tube with an internal helical element. International Chemical Engineering, 27, 210-217.

Lee. S., Choi, S. U. S., Li, S., \& Eastman, J. A. (1999). Measuring thermal conductivity of fluids containing oxide nanoparticles. Journal of heat transfer, 121, 208-289.

Lopina, R. F., \& Bergles, A. E. (1969). Heat transfer and pressure drop in tapegenerated swirl flow of single phase water. Journal of Heat Transfer, 91, 434442.

Masuda, H., Ebata, A., Teramae, K., \& Hishinuma, N. (1993). Altration of thermal conductivity and viscosity of liquid by dispersing ultra-fine particles (dispersion of $\gamma-\mathrm{Al}_{2} \mathrm{O}_{3}, \mathrm{SiO}_{2}$ and $\mathrm{TiO}_{2}$ ultra-fine particles). Netsu Bussei (in Japanese), 4(4), 227-233.

Moody, L. F. (1944). Friction factor for pipe flow. Transactions of ASME, 66, 671684.

Namburu, P. K., Das, D. K., Tanguturi, K. M., \& Vajjha, R. K. (2009). Numerical study of turbulent flow and heat transfer characteristics of nanofluids considering variable properties. International Journal of Thermal Sciences, 48(2), 290-302.

Pak, B. C., \& Cho, Y. I. (1998). Hydrodynamic and heat transfer study of dispersed fluids with submicron metallic oxide particles. Experimental Heat Transfer, 11, 151-170.

Palm, S. J., Roy, G., \& Nguyen, C. T. (2004). Heat transfer enhancement in radial flow cooling system-using nanofluid. In: Proceeding of the ICHMT Inter. Symp. Advance Comp. Heat Transfer, Norway, CHT-04-121.

Roy, G., Nguyen, C. T., \& Lajoie, P. R. (2004). Numerical investigation of laminar flow and heat transfer in a radial flow cooling system with the use of nanofluids. Superlattices and Microstructures, 35(3), 497-511.

Sarma, P. K., Subramanyam, T., Kishore, P. S., Dharma Rao, V., \& Kakac, S. (2003). Laminar convective heat transfer with twisted tape inserts in a tube, International Journal of Thermal Sciences, 42, 821-828.

Sharma, K. V., Sundar, L. S., \& Sarma, P. K. (2009). Estimation of heat transfer coefficient and friction factor in the transition flow with low volume concentration of $\mathrm{Al}_{2} \mathrm{O}_{3}$ nanofluid flowing in a circular tube and with twisted tape insert. International Communications in Heat and Mass Transfer, 36, 503-507.

Smithberg, E., \& Landis, F. (1964). Friction and forced convective heat transfer characteristics in tube with twisted-tape swirl generators. Journal of Heat Transfer, 86, 39-49.

Sundar, L. S., Ramanathan, S., Sharma, K. V., \& Sekhar Babu, P. (2007). Temperature dependent flow characteristics of $\mathrm{Al}_{2} \mathrm{O}_{3}$ nanofluid. International Journal of Nanotechnology and Applications, 1(2), 35-44.

Sundar, L. S., \& Sharma, K. V. (2008). Thermal conductivity enhancement of nanoparticles in distilled water. International Journal of Nanoparticles, 1(1), 66-77.

Sundar, L. S., \& Sharma, K. V. (2010). Turbulent heat transfer and friction factor of $\mathrm{Al}_{2} \mathrm{O}_{3}$ nanofluid in circular tube with twisted tape inserts. International Journal of Heat and Mass Transfer, 53, 1409-1416. 
Wang, X, Q., \& Mujumdar, A. S. (2007). Heat transfer characteristics of nanofluids: a review. International Journal of Thermal Sciences, 46, 1-19.

Wang, X., Xu, X., \& Choi, S. U. S. (1999). Thermal conductivity of nanoparticles-fluid mixture. Journal of Thermophysics Heat Transfer, 13(4), 474-480.

Wen, D., \& Ding, Y. (2004). Experimental investigation into convective heat transfer of nanofluid at the entrance region under laminar flow conditions. International Journal of Heat and Mass Transfer, 47(24), 5181-5188.

Xuan, Y., \& Li, Q. (2003). Investigation on convective heat transfer and flow features of nanofluids. Journal of Heat Transfer, 125, 151-155.

\section{Nomenclature}

A area, $\mathrm{m}^{2}$

C specific heat, $\mathrm{J} / \mathrm{kg} \mathrm{K}$

$D \quad$ inner diameter of the tube, $\mathrm{m}$

$f \quad$ friction factor

$h \quad$ convective heat transfer coefficient, $\mathrm{W} / \mathrm{m}^{2} \mathrm{~K}$

I current, Amp

$k$ thermal conductivity, $\mathrm{W} / \mathrm{m} \mathrm{K}$

$L \quad$ length of the tube, $\mathrm{m}$

$\dot{m} \quad$ mass flow rate, $\mathrm{kg} / \mathrm{s}$

$\mathrm{Nu} \quad$ Nusselt number, $h D / k$

Pr Prandtl Number, $\mu C / k$

Re Reynolds number, $\frac{4 \dot{m}}{\pi D \mu}$

$T$ temperature, ${ }^{\circ} \mathrm{C}$

$V \quad$ voltage, volts

$\mathrm{v} \quad$ velocity, $\mathrm{m} / \mathrm{sec}$

Greek symbols

$\Delta P$ pressure drop across the tube

$\phi \quad$ volume concentration of nanoparticles, $\%$

$\mu \quad$ dynamic viscosity, $\mathrm{kg} / \mathrm{m}^{2} \mathrm{~s}$

$\rho$ density, $\mathrm{kg} / \mathrm{m}^{3}$

\begin{tabular}{ll}
\multicolumn{2}{l}{ Subscripts } \\
Exp & experimental \\
h & hydraulic diameter \\
i & inner diameter \\
m & mean \\
Reg & regression \\
W & wall
\end{tabular}

